\title{
The combination of single-dose montelukast and loratadine on exercise-induced bronchospasm in children
}

\author{
D.G. Peroni*, G.L. Piacentini*, A. Pietrobelli*, A. Loiacono*, W. De Gasperi*, A. Sabbion*, \\ R. Micciolo", A.L. Boner*
}

\begin{abstract}
The combination of single-dose montelukast and loratadine on exercise-induced bronchospasm in children. D.G. Peroni, G.L. Piacentini, A. Pietrobelli, A. Loiacono, W. De Gasperi, A. Sabbion, R. Micciolo, A.L. Boner. (C) ERS Journals Ltd 2002.

ABSTRACT: The aim of the study was to evaluate the protective effect of single-dose, combination treatment comprising montelukast $(5 \mathrm{mg})$ and loratadine $(10 \mathrm{mg})$, on exercise-induced bronchoconstriction in asthmatic children. The combination was compared to placebo, loratadine and montelukast alone.

Nineteen children were enrolled in a double-blind randomised, single-dose, crossover study. For each treatment patients undertook two treadmill exercise tests, 2 and 12 h respectively after single-dose administration.

No significant differences were seen in the maximum fall in forced expiratory volume in one second (FEV1) $2 \mathrm{~h}$ after treatment and placebo. Whereas significant differences in maximum fall in FEV1 were observed between treatment groups $12 \mathrm{~h}$ after administration. Loratadine alone did not show any significant protection or any additional effect in comparison with montelukast alone. Single doses of montelukast and montelukast plus loratadine were significantly more effective than loratadine at $12 \mathrm{~h}$.

The present study, performed using single-dose treatments, demonstrated that maximal protective effect by montelukast was obtained $12 \mathrm{~h}$ after dosing and that montelukast plus loratadine did not result in significant additive bronchoprotective effects on exercise-induced bronchoconstriction.

Eur Respir J 2002; 19: 104-107.
\end{abstract}

* Clinica Pediatrica, University of Verona, Verona, ${ }^{\#}$ Istituto Pio XII, Misurina and "Dept of Statistics, University of Trento, Trento, Italy.

Correspondence: P. Diego

Clinica Pediatrica Universita'

di Verona,

Policlinico GB Rossi

Via Menegone

37134 Verona

Italy

Fax: 390458200993

E-mail: peroni.diego@tiscalinet.it

Keywords: Asthma

childhood

exercise-induced bronchoconstriction

loratadine

montelukast

Received: April 172001

Accepted after revision: March 12002
The role of leukotrienes in asthma is demonstrated by several studies showing positive prechallenge effects by leukotriene-receptor antagonists (LTRAs) in exercise- [1, 2] and allergen-induced bronchoconstriction [3]. The LTRAs, such as montelukast, provide protection against exercise-induced bronchoconstriction (EIB) attenuating the fall in pulmonary function following exercise with no induced tachiphylaxis. $\beta_{2}$-agonists are highly effective in reducing the symptoms. However, recent studies highlighted that the extent of protection diminishes with their exclusive regular use after 6-8 weeks both for short-acting and long-acting agonists (reviewed in [4]). Histamine has been implicated in EIB but antihistamines have been shown to offer modest protection against EIB [5]. However, there is some evidence that combined mediator blockade with both leukotriene and histamine-receptor antagonists results in greater symptom control than LTRAs alone in patients with persistent asthma [6]. In fact, it has been demonstrated that cysteinyl-leukotrienes and histamine synergise in vitro as immunoglobulin (Ig) E-dependent bronchoconstriction mediators [7]. Furthermore, the combination of zafirlukast, a leukotriene antagonist, and loratadine was significantly more effective than either drug alone during allergen-induced early and late obstruction [3]. The aim of this study was to investigate if single doses of the combination of a LTRA, montelukast, and a histamine-receptor antagonist, loratadine, may determine an addictive protective effect on EIB in children in comparison to either drug alone.

\section{Methods}

\section{Patients}

Allergic-asthmatic children ( $\mathrm{n}=19)$ with a positive clinical history of EIB were evaluated whilst living at high altitude in the Italian Alps, in a house dust mite-free environment. The patient characteristics are summarised in table 1. Because of the effects of prolonged stay at high altitude none of the patients were receiving inhaled or oral steroids, antihistamines or antileukotrienes. The patients had not presented with infectious diseases of the upper airways in the previous month. $\beta_{2}$-agonists were allowed for as-needed medication until at least $12 \mathrm{~h}$ before the challenges. On the day of admission to the study the subjects performed baseline exercise challenges at 10:00 and $20.00 \mathrm{~h}$. A fall in the forced expiratory volume in one second (FEV1) after exercise of $\geqslant 15 \%$ of the pre-exercise value was considered diagnostic of EIB. 
Table 1. - Patient characteristics

\begin{tabular}{|c|c|c|c|c|c|c|c|}
\hline $\begin{array}{l}\text { Patient } \\
\text { no. }\end{array}$ & Age yrs & Sex & Height $\mathrm{cm}$ & Weight $\mathrm{kg}$ & $\begin{array}{c}\text { Asthma } \\
\text { duration yrs }\end{array}$ & $\begin{array}{c}\text { FEV1 at } \\
\text { recruitment \% }\end{array}$ & $\begin{array}{l}\text { Methacholine } \\
\text { PC20 } \mathrm{mg} \cdot \mathrm{mL}^{-1}\end{array}$ \\
\hline 1 & 11 & M & 140 & 39 & 7 & 84 & 2.2 \\
\hline 2 & 13 & M & 160 & 59 & 10 & 101 & 12.0 \\
\hline 3 & 13 & $\mathrm{M}$ & 159 & 59 & 8 & 95 & 12.0 \\
\hline 4 & 11 & M & 137 & 35 & 9 & 87 & 2.5 \\
\hline 5 & 8 & $\mathrm{M}$ & 131 & 35 & 5 & 76 & 1.06 \\
\hline 6 & 12 & M & 151 & 44 & 6 & 95 & 6.5 \\
\hline 7 & 11 & M & 151 & 36 & 5 & 80 & 5.3 \\
\hline 8 & 11 & M & 145 & 42 & 7 & 77 & 0.27 \\
\hline 9 & 13 & $\mathrm{~F}$ & 150 & 45 & 10 & 76 & 3.5 \\
\hline 10 & 11 & $\mathrm{~F}$ & 132 & 31 & 6 & 80 & 12.0 \\
\hline 11 & 13 & $\mathrm{~F}$ & 158 & 53 & 10 & 84 & 12.0 \\
\hline 12 & 10 & M & 142 & 45 & 7 & 83 & 0.8 \\
\hline 13 & 9 & $\mathrm{~F}$ & 136 & 30 & 5 & 87 & 2.5 \\
\hline 14 & 13 & $\mathrm{~F}$ & 152 & 70 & 8 & 89 & 1.4 \\
\hline 15 & 7 & M & 134 & 32 & 4 & 104 & 9.0 \\
\hline 16 & 10 & M & 151 & 59 & 5 & 88 & 7.5 \\
\hline 17 & 13 & M & 173 & 70 & 8 & 91 & 6.5 \\
\hline 18 & 10 & $\mathrm{~F}$ & 137 & 36 & 6 & 103 & 12.0 \\
\hline 19 & 12 & $\mathrm{M}$ & 155 & 40 & 6 & 87 & 6.4 \\
\hline
\end{tabular}

FEV1: forced expiratory volume in one second; PC20: provocative concentration causing a 20\% fall in FEV1; M: male; F: female.

\section{Study design}

The study was performed during the winter in order to eliminate the influence of pollens. A double-blind randomised, single-dose, crossover design was used. For each patient four double-blind randomised singledose treatments of placebo, loratadine, montelukast and the combination montelukast plus loratadine, were administered on four different days at 08:00 h. Each patient undertook two treadmill exercise tests following each drug administration $2(10: 00 \mathrm{~h})$ and $12 \mathrm{~h}(20: 00 \mathrm{~h})$ after dosing. Each drug administration and the following exercise tests were performed 3-5 days apart.

\section{Treadmill exercise tests}

Children performed a baseline spirometry and then ran for $6 \mathrm{~min}$ on a treadmill, at speed, to obtain an increase of $80 \%$ in their maximum cardiac frequency in a specially designated room with constant temperature $\left(21^{\circ} \mathrm{C}\right)$ and humidity $(40-50 \%)$. Following the exercise challenge, FEV1 was obtained at 1, 5, 10, 15, 20 and $30 \mathrm{~min}$. To assess bronchoconstriction after the exercise challenge, the maximal percentage fall in FEV1 $(\triangle \mathrm{FEV} 1)$ from the baseline value and the area under the curve (AUC0-30min) with percentage change in FEV1 data over time were considered. Percentage of protection was calculated as:

$$
\mathrm{P}_{\mathrm{s}}-\mathrm{P}_{\mathrm{t}} / \mathrm{P}_{\mathrm{s}}
$$

where $P_{s}$ is the percentage fall in FEV1 at the screening visit, and $\mathrm{Pt}$ is the fall after each treatment. Clinical protection was considered to be obtained if the percentage fall after receiving active drug was one-half or less of the percentage fall after receiving placebo.

\section{Statistical analysis}

The effects of treatment on the response to exercise challenge were compared using $\triangle F E V 1$ expressed as the percentage of the prechallenge baseline. An analysis of variance model for repeated measures (ANOVA) in a crossover design was used to compare treatment groups. The hospitals' ethical committee approved the study and the parents gave informed consent.

\section{Results}

\section{Safety}

No adverse effects on safety were observed during the study period.

\section{Efficacy}

There was no significant difference between patients' baseline FEV1 after each drug administration (table 2). The $\triangle \mathrm{FEV} 1$ during the screening test, expressed as mean \pm SEM, were: $-22.84 \pm 3.01$ at 10:00 $\mathrm{h}$ and $-21.31 \pm 2.60$ at $20.00 \mathrm{~h}$.

When the exercise test was performed $2 \mathrm{~h}$ after the drug administration the $\triangle F E V 1$ was $-15.33 \pm 2.93$ for placebo, $-13.9 \pm 2.67$ for loratadine, $-13.33 \pm 2.03$ for montelukast and $-10.07 \pm 1.96$ for the combination, with no significant differences. At $12 \mathrm{~h}$ the $\triangle \mathrm{FEV} 1$ was $-18.69 \pm 2.83$ for placebo, $-14.64 \pm 2.55$ for loratadine, $-9.78 \pm 1.85$ for montelukast and $-9.51 \pm 2.55$ for montelukast plus loratadine. Significant differences were observed between placebo and montelukast $(\mathrm{p}<0.02)$, placebo and the combined treatment $(p<0.02)$ and between respectively montelukast and 
Table 2. - Baseline forced expiratory volume in one second (FEV1) with the different exercise-challenge tests

\begin{tabular}{|c|c|c|c|c|c|c|c|c|c|c|}
\hline \multirow{2}{*}{$\begin{array}{l}\text { Patient } \\
\text { no. }\end{array}$} & \multicolumn{2}{|c|}{ Screening } & \multicolumn{2}{|c|}{ Placebo } & \multicolumn{2}{|c|}{ Loratadine } & \multicolumn{2}{|c|}{ Montelukast } & \multicolumn{2}{|c|}{ Montelukast+Loratadine } \\
\hline & $2 \mathrm{~h}$ & $12 \mathrm{~h}$ & $2 \mathrm{~h}$ & $12 \mathrm{~h}$ & $2 \mathrm{~h}$ & $12 \mathrm{~h}$ & $2 \mathrm{~h}$ & $12 \mathrm{~h}$ & $2 \mathrm{~h}$ & $12 \mathrm{~h}$ \\
\hline 1 & 1.79 & 1.72 & 1.69 & 1.58 & 1.66 & 1.67 & 1.79 & 1.70 & 1.68 & 1.79 \\
\hline 2 & 3.14 & 3.00 & 3.23 & 3.20 & 3.10 & 3.07 & 3.21 & 3.04 & 3.27 & 3.16 \\
\hline 3 & 2.91 & 2.89 & 2.98 & 2.96 & 2.91 & 2.95 & 3.04 & 2.87 & 3.08 & 2.87 \\
\hline 4 & 1.75 & 1.94 & 1.78 & 1.66 & 1.62 & 1.74 & 1.75 & 1.76 & 1.77 & 1.83 \\
\hline 5 & 1.36 & 1.64 & 1.58 & 1.56 & 1.62 & 1.53 & 1.70 & 1.79 & 1.86 & 1.81 \\
\hline 6 & 2.36 & 2.18 & 2.28 & 2.18 & 2.30 & 2.11 & 2.46 & 2.40 & 2.31 & 2.23 \\
\hline 7 & 2.11 & 2.19 & 2.22 & 2.19 & 2.18 & 2.16 & 2.07 & 2.20 & 2.00 & 2.09 \\
\hline 8 & 1.66 & 1.77 & 1.74 & 1.72 & 1.77 & 1.80 & 1.68 & 1.71 & 1.94 & 1.93 \\
\hline 9 & 1.98 & 2.21 & 1.90 & 2.13 & 2.19 & 1.99 & 2.14 & 2.20 & 2.15 & 1.96 \\
\hline 10 & 1.44 & 1.33 & 1.57 & 1.57 & 1.61 & 1.50 & 1.71 & 1.68 & 1.63 & 1.54 \\
\hline 11 & 2.53 & 2.49 & 2.64 & 2.61 & 2.52 & 2.60 & 2.62 & 2.67 & 2.76 & 2.79 \\
\hline 12 & 1.86 & 1.78 & 1.95 & 1.73 & 1.71 & 1.90 & 2.07 & 1.96 & 2.19 & 2.09 \\
\hline 13 & 1.71 & 1.62 & 1.51 & 1.55 & 1.68 & 1.64 & 1.63 & 1.62 & 1.69 & 1.70 \\
\hline 14 & 2.40 & 2.60 & 2.35 & 2.48 & 2.33 & 2.25 & 2.45 & 2.45 & 2.54 & 2.42 \\
\hline 15 & 1.98 & 1.84 & 1.88 & 1.81 & 1.94 & 2.00 & 1.92 & 1.91 & 1.94 & 1.83 \\
\hline 16 & 2.43 & 2.42 & 2.17 & 2.39 & 2.76 & 2.31 & 2.29 & 2.14 & 2.32 & 2.41 \\
\hline 17 & 3.53 & 3.29 & 3.66 & 3.75 & 3.84 & 3.46 & 3.68 & 3.49 & 3.40 & 3.56 \\
\hline 18 & 2.10 & 1.95 & 1.89 & 1.95 & 2.06 & 2.00 & 2.07 & 1.95 & 1.86 & 1.88 \\
\hline 19 & 2.52 & 2.16 & 2.71 & 2.73 & 2.83 & 2.75 & 2.92 & 2.93 & 2.85 & 2.89 \\
\hline
\end{tabular}

the combination in comparison to loratadine $(\mathrm{p}<$ $0.05)$. No significant difference was observed between placebo and loratadine.

At $2 \mathrm{~h}$ AUC0-30min, ( $\% \mathrm{x}$ min) expressed as mean \pm SEM, was $-34.32 \pm 11.5 \%$ for placebo, $-50.66 \pm 20.46 \%$ for loratadine, $-23.74 \pm 10.06 \%$ for montelukast and $-18.87 \pm 7.14 \%$ for the combination, with no significant differences. When the challenges were performed $12 \mathrm{~h}$ after the drug administration, AUC0-30min was $-43.60 \pm 9.34 \%$ after placebo, $-39.6 \pm 10.89 \%$ after loratadine, $-15.03 \pm 5.38 \%$ after montelukast and $-7.76 \pm 6.14 \%$ after the combination, with significant differences between montelukast and montelukast plus loratadine in comparison to placebo $(\mathrm{p}<0.01)$ and to loratadine alone $(=0.02)$.

\section{Protection}

At $2 \mathrm{~h}$ after dose administration, no significant difference in the percentage of protection was observed between placebo (33\%), loratadine (43\%), montelukast $(47 \%)$ and montelukast plus loratadine $(59 \%)$. At $12 \mathrm{~h}$ there was a significant difference in the percentage of protection between placebo $(20 \%)$ and montelukast $(63 \%)(\mathrm{p}<0.01)$, and between placebo and the combination $(59 \%)(\mathrm{p}<0.01)$, but not between placebo (20\%) and loratadine (45\%). Montelukast provided clinical protection in three subjects $(15 \%)$ at $2 \mathrm{~h}$ and in 12 subjects $(63 \%)$ at $12 \mathrm{~h}$. The combination of the two drugs gave a similar trend with clinical protection in six subjects $(31 \%)$ at $2 \mathrm{~h}$, and in 12 subjects $(63 \%)$ at $12 \mathrm{~h}$.

\section{Discussion}

The aim of the study was to verify if the association of a LTRA, montelukast, plus an antihistaminic drug, loratadine, may exert an additive effect in the prevention of EIB. It has been previously shown that LTRAs are able to protect against early and late allergen-induced responses, even without any changes in inflammatory indices such as sputum eosinophil percentage or activity [8]. Furthermore, it has been demonstrated that the combination loratadine and zafirlukast, inhibited both early and late reactions following allergen challenge by $\sim 75 \%$ [3]. As the efficacy has appeared to begin acutely, different antiinflammatory mechanisms might be involved including effects on the vascular system, the airway oedema, mucous production and neurogenic inflammation [9]. These events may also contribute to the development of the hypertonicity of airway lining fluid which seems to be the major determinant of EIB, determining mediator release by inflammatory cells. In the present study, the authors analysed drug efficacy at 2 and $12 \mathrm{~h}$, and the effects of the combination at the beginning and the end of a once-daily single dosage were investigated. In several studies two or more doses of montelukast were used in order to achieve steady-state blood levels [1, 2]. In the present study the use of a single administration of drugs was adopted in an attempt to clarify, as much as possible, the contribution of both antileukotriene and antihistaminic drugs in the protection from EIB. To the best of the authors' knowledge this is the first study examining the effect of a single dose of montelukast and loratadine alone and in combination. No statistically significant additive effect using the combination of the two drugs in comparison to montelukast alone was obtained. However, results showed that even after $2 \mathrm{~h}$ there was a trend towards protection when the children were treated with the combination. Mean values of the $\triangle F E V 1$ and the percentage of protection obtained after both drug administration ( 2 and $12 \mathrm{~h}$ respectively) did not change significantly, but at $2 \mathrm{~h}$ there was a strong placebo effect. This effect in EIB has been described 
previously in children, and it has been characterised by dose and duration time effect [10]. At $12 \mathrm{~h}$ montelukast and the combination were significantly more effective than placebo and loratadine alone.

To conclude, the combination of montelukast and loratadine single-dose administration, demonstrated no additive effect in exercise-induced bronchoconstriction protection. However, since antileukotrienes in association with antihistamines have been demonstrated to provide a significant improvement in chronic asthma [6] and allergic rhinitis [11, 12] in adults, combined and prolonged oral therapy should also be evaluated in children. Further studies are necessary to evaluate long-term clinical effects of this and other therapeutic combinations on asthma and exercise-induced bronchoconstriction in childhood.

\section{References}

1. Kemp JP, Dockhorn RJ, Shapiro G, et al. Montelukast once daily inhibits exercise-induced bronchoconstriction in 6- to 14-year-old children with asthma. J Pediatr 1998; 133: 424428.

2. Pearlman D, Ostrom N, Bronsky E, Bonuccelli C, Hanby L. The leukotriene D4-receptor antagonist zafirlukast attenuates exercise-induced bronchoconstriction in children. J Pediatr 1999; 134: 273 279.

3. Roquet A, Dahlen B, Kumlin M, et al. Combined antagonism of leukotrienes and histamine produces predominant inhibition of allergen-induced early and late phase airway obstruction in asthmatics. $\mathrm{Am}$ J Respir Crit Care Med 1997; 155: 1856-1863.

4. Bisgaard $\mathrm{H}$. Long-acting $\beta_{2}$ agonists in management of childhood asthma: a critical review of the literature. Ped Pulmonol 2000; 29: 221-224.
5. Gong H, Tashkin DP, Dauphinee B, Djahed B, Wu T. Effects of oral cetirizine, a selective $\mathrm{H}_{1}$ antagonist, on allergen- and exercise-induced bronchoconstriction in subjects with asthma. J Allergy Clin Immunol 1990; 85: 632-641.

6. Reicin AS, White R, Weinstein SF, et al. Montelukast, a leukotriene receptor antagonist, in combination with loratadine, a histamine receptor antagonist, in the treatment of chronic asthma. Arch Intern Med 2000; 160: 2481-2488.

7. Bjorck T, Dahlen S. Leukotrienes and histamine mediate IgE-dependent contractions of human bronchi: pharmacological evidence obtained with tissues from asthmatic and non-asthmatic subjects. Pulm Pharmacol 1993; 6: 87-96.

8. Diamant Z, Grootendorst D, Veselic-Charvat $\mathrm{M}$, et al. The effect of montelukast (MK-0476), a cysteinyl leukotriene receptor antagonist, on allergen-induced airway responses and sputum cell counts in asthma. Clin Exp Allergy 1999; 29: 42-51.

9. Wenzel SE. Inflammation, leukotrienes and the pathogenesis of the late asthmatic response. Clin Exp Allergy 1999; 29: 1-3.

10. Boner AL, Vallone G, Peroni D, Piacentini G, Gaburro D. Efficacy and duration of action of placebo responses in the prevention of exerciseinduced asthma in children. $J$ Asthma 1988; 25: 1-5.

11. Meltzer EO, Malmstrom K, Lu S, et al. Concomitant montelukast and loratadine as treatment for seasonal allergic rhinitis: a randomized, placebo-controlled clinical trial. J Allergy Clin Immunol 2000; 105: 917922.

12. Wilson AM, LC Orr, EJ Sims, Lipworth BJ. Effects of monotherapy with intra-nasal corticosteroid or combined oral histamine and leukotriene receptor antagonists in seasonal allergic rhinitis. Clin Exp Allergy 2001; 31: 61-68. 